\title{
DIREITOS HUMANOS: REPRESENTAÇÕES DISCURSIVAS NAS VOZES DE POLICIAIS MILITARES
}

\section{Cristiane C. de Paula Brito* Davi de Brito Júnior* *}

Resumo: Este artigo visa investigar representações discursivas acerca do conceito de Direitos Humanos construídas por policiais militares, no intuito de problematizar a incidência dessa discursividade nos cursos de formação e treinamento desses profissionais. Partimos da hipótese de que há tensão entre o discurso institucional e o discurso não legitimado institucionalmente, independentemente do período de formação do sujeito policial.

Palavras-chave: Direitos Humanos. Análise do Discurso. Formação Policial.

\section{Palavras iniciais}

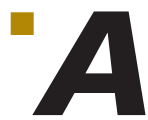

o pautar sua identidade organizacional no respeito aos direitos humanos, a instituição Polícia Militar procura fundamentar suas ações na proteção à vida e à dignidade do homem. Nesse sentido, a questão dos Direitos Humanos necessita ser debatida na formação do policial, haja vista que seu conceito jurídico e sua operacionalização trazem implicações para a prática desse profissional.

Mendonça Filho et al. (2002) salientam o lugar privilegiado dado à discussão sobre os direitos humanos nos debates públicos atuais e destacam que eles podem ser vistos como "uma verdadeira 'ideologia' contemporânea, na medida em que eles tendem a ser uma espécie de discurso oficial de nossa época, paradigma elocutório para o qual diversos grupos convergem, se não no plano da prática, pelo menos em termos retóricos" (p. 95). Com base na compreensão de que

\footnotetext{
* Universidade Federal de Uberlândia (UFU) - Uberlândia - MG - Brasil. E-mail: depaulabrito@gmail.com

** Universidade Cruzeiro do Sul (Unicsul) - São Paulo - SP - Brasil.
} 
é pela linguagem que se constroem identidades, inclusive profissionais; (re)produzem-se conhecimentos; estabelecem-se relações de poder, enfim, que práticas sociais são consolidadas, este trabalho se propõe a investigar e compreender as vozes mobilizadas por policiais militares (PM) ao enunciarem sobre o tema Direitos Humanos.

Sob um viés discursivo de linguagem, nosso objetivo é delinear as representações discursivas acerca do conceito de Direitos Humanos, problematizando suas incidências nos cursos de formação e treinamento desses profissionais. Partimos da hipótese de que há tensão entre o discurso institucional e o discurso não legitimado institucionalmente, independentemente do período de formação do sujeito policial.

Para dar conta dessa empreitada, iniciaremos com algumas palavras sobre o conceito de Direitos Humanos; em seguida, explicitaremos o escopo teórico-metodológico que fundamenta a pesquisa. Passaremos, então, à discussão das análises e teceremos algumas considerações finais.

\section{Algumas palavras sobre os Direitos humanos}

A Declaração Universal dos Direitos Humanos (DUDH), proclamada pela Assembleia Geral das Nações Unidas em Paris, em 1948, configura-se como um marco na história dos direitos humanos ao propor a proteção universal destes, "considerando que o reconhecimento da dignidade inerente a todos os membros da família humana e dos seus direitos iguais e inalienáveis constitui o fundamento da liberdade, da justiça e da paz no mundo" ${ }^{\prime \prime}$.

Ferreira Filho (2007) aponta a existência de três gerações de direitos, demonstrando claramente a evolução da preocupação histórica com os Direitos Humanos. Em suas palavras,

o que aparece no final do século XVII não constitui senão a primeira geração dos direitos fundamentais: as liberdades públicas. A segunda virá logo após a primeira Guerra Mundial, com o fito de complementá-la: são os direitos sociais. A terceira, ainda não plenamente reconhecida é a dos direitos de solidariedade. (FERREIRA FILHO, 2007, p. 6)

Benevides (2000) aponta as seguintes características dos Direitos Humanos: naturais e universais, uma vez que estão atrelados à essência do ser humano; interdependentes e indivisiveis, o que diz respeito ao fato de que devem ser considerados em sua dimensão individual e social; e históricos, haja vista sua transformação ao longo de diferentes períodos. A noção de Direitos Humanos não pode, portanto, ser concebida por uma perspectiva estática (HERKENHOFF, 1997). Na verdade, ela vai sendo ressignificada ao longo da história da humanidade à luz das revoluções, das lutas sociais e das diferentes formas com que os povos percebem a importância do respeito aos seres humanos.

No contexto brasileiro, mais especificamente, viveu-se a Ditadura Militar de 1964 a 1985, que termina com as eleições indiretas para presidente em 1984 quando foi eleito Tancredo Neves. Essas eleições indiretas foram precedidas de

1 Disponível em: <http://pt.wikisource.org/wiki/Declara\%C3\%A7\%C3\%A3o_Universal_dos_Direitos_Humanos. Acesso 04/12/2014>. 
uma enorme campanha popular em favor de eleições diretas denominada de Diretas já. O Regime Militar, com justificativas de combater a subversão e a corrupção, suprimiu direitos constitucionais, perseguiu e censurou os meios de comunicação, extinguiu os partidos politicos e criou o bipartidarismo. Após o fim do regime militar, os deputados federais e senadores se reuniram em 1988, em Assembleia Nacional Constituinte, e promulgaram a nova Constituição, que ampliava os direitos individuais. Balestreri afirma que

durante muitos anos o tema Direitos Humanos foi considerado antagônico ao de Segurança Pública. Produto do autoritarismo vigente no país entre 1964 e 1984 e da manipulação, por ele, dos aparelhos policiais, esse velho paradigma maniqueísta cindiu, sociedade e polícia, como se a última não fizesse parte da primeira. (BALESTRERI, 2003, p. 21).

Ao longo dos anos, a sociedade brasileira passou por grandes transformações políticas, econômicas e sociais que contribuíram para a construção da Constituição Federal do Brasil promulgada em 1988. Um olhar para a história do Brasil nos permite perceber como ocorreram as lutas das diversas classes sociais desde o início da colonização portuguesa. Em nosso país, o poder se alternou entre as monarquias, as oligarquias e os militares. Saímos da escravidão, passamos pela exploração de trabalhadores sem concessão de direitos sociais e atualmente vivemos em uma sociedade democrática, que experiência a intensa reflexão sobre Direitos Humanos no intuito de melhorar a qualidade de vida do povo brasileiro.

A legislação brasileira tem demonstrado preocupação com a proteção dos Direitos Humanos não apenas na Constituição Federal - a qual é bem incisiva com relação à proteção de diversos direitos fundamentais dos cidadãos ${ }^{2}$ - mas também na complementação de leis especiais, como o Estatuto da Criança e do Adolescente (ECA), o Estatuto do Idoso e a Lei Maria da Penha, dentre outras.

Em 1996, o governo federal cria o Programa Nacional de Direitos Humanos I (PNDH-1) com vistas a direcionar ações mais efetivas para sua aplicação. A implementação das diretrizes desse Programa, ao longo dos últimos anos, abriu novas perspectivas de transformação no modo como a sociedade brasileira se comporta no seu cotidiano, na busca constante por justiça e por melhores condições de vida. Fortaleceram-se as garantias de que dispõem os brasileiros DPSSP n ${ }^{\circ}$ 3.01.05/2010, contra o arbítrio do Estado, a prática da violência e o desrespeito dos direitos fundamentais.

A Instituição Polícia Militar de Minas Gerais (PMMG), de acordo com a Diretriz para a Produção de Serviços de Segurança Pública (DPSSP) n 3.01.05, de 2010, possuía documentos normativos desde 1984, como a Nota Instrutiva $n^{\circ}$ 001/84, que tratava sobre Direitos Humanos e tinha como determinação o respeito à pessoa qualquer fosse a sua condição. A partir da promulgação da

\footnotetext{
2 A título de exemplo, podemos citar o Artigo $3^{\circ}$ da Constituição Federal, que destaca como objetivo fundamental o tratamento igual a todos os seres humanos, defendendo claramente os Direitos Humanos: "Artigo $3^{\circ}-$ Constituem objetivos fundamentais da República Federativa do Brasil: IV - promover o bem de todos, sem preconceitos de origem, raça, sexo, cor, idade e quaisquer outras formas de discriminação." (BRASIL, 2007, p. 3). O artigo $5^{\circ}$ destaca que "todos são iguais perante a lei, sem distinção de qualquer natureza, garantindo-se aos brasileiros e aos estrangeiros residentes no País a inviolabilidade do direito à vida, à liberdade, à igualdade, à segurança e à propriedade [...]" (BRASIL, 2007, p. 5).
} 
Constituição Federal de 1988, a PMMG reforça o discurso temático de Direitos Humanos nos cursos de formação dos policiais militares.

Em 1998, o Comitê Internacional da Cruz Vermelha (CICV), em parceria com o Ministério da Justiça e os comandos das Polícias Militares, iniciam um projeto de ampliação dos conhecimentos teóricos e técnicos para a atuação policial militar em sintonia com as normas internacionais de Direitos Humanos. A partir de 1998, vários cursos são realizados, capacitando professores Multiplicadores de Direitos Humanos que espalham por todo o Estado as doutrinas e comportamentos técnicos mais sólidos para os PMs exercerem sua missão institucional. Em 2004, entra em vigor a primeira versão da diretriz de Direitos Humanos da PMMG. Desde então, a instituição vem formando e treinando seus policiais militares com a intensificação de diretrizes fundamentadas na filosofia de Direitos Humanos com o objetivo de torná-los protetores e promotores desses direitos, haja vista que "o policial é antes de tudo um cidadão, e na cidadania deve nutrir sua razão de ser" (BALESTRERI, 2003, p. 22), sendo infundada a dualidade "sociedade civil" e outra "sociedade policial".

\section{Escopo TEÓRICo e PERCURSO MetodológICo DA PESQUISA}

Este trabalho fundamenta-se nos pressupostos teóricos da Análise do Discurso de linha francesa em interface com concepções bakhtinianas de linguagem (BAKHTIN/VOLOCHINOV, 1929/2002; BAKHTIN, 1929/2008, 1953/2003). Essa articulação nos permite mobilizar conceitos como os de linguagem, sujeito, sentido, discurso, memória discursiva, polifonia e dialogismo na constituição e análise do corpus.

A fim de que seja possivel um novo olhar para as falas das pessoas entrevistadas, tomou-se a noção de linguagem sob uma perspectiva que a considera, não como simples instrumento de comunicação ou como sistema fechado de estruturas gramaticais, mas assume-se que "a linguagem serve para comunicar e para não comunicar. As relações de linguagem são relações de sujeitos e de sentidos e seus efeitos são múltiplos e variados" (ORLANDI, 2005, p. 21). Efeito devido ao fato de que o sentido pode sempre deslizar, isto é, ser outro, sendo impossivel o seu fechamento.

A linguagem é essencialmente dialógica e polifônica (BAKHTIN/VOLOCHINOV, 1929/2002; BAKHTIN, 1929/2008; 1953/2003). Isto é, as palavras não são propriedades exclusivas (ou originárias) dos sujeitos que as enunciam, pois os dizeres são produzidos sócio-historicamente, a partir de normas socioculturais estabelecidas, que limitam, de certa forma, as próprias possibilidades de significação. Assim,

toda palavra serve de expressão a um em relação ao outro. Através da palavra, defino-me em relação ao outro, isto é, em última análise, em relação à coletividade. A palavra é uma espécie de ponte lançada entre mim e os outros. Se ela se apóia sobre mim numa extremidade, na outra apóia-se sobre o meu interlocutor. A palavra é o território comum do locutor e do interlocutor. (BAKHTIN, 1929/2002, p. 115)

Todo dizer traz à tona vozes que advêm de distintos lugares sócioideológicos, ressoando discursos que se contradizem e se confrontam, já que evocam memó- 
rias, já ditos que são ressignificados e (des)atualizados na tomada da palavra. O sujeito tem a ilusão de ser a origem do que diz, 'esquecendo-se' de que suas palavras não são nunca (totalmente) suas, pois a lingua (e a possibilidade de qualquer sentido) se inscreve na história ${ }^{3}$.

Da perspectiva teórica aqui assumida, nos interessa investigar não o conteúdo (a 'informação') dos dizeres, mas os discursos colocados em funcionamento por meio das vozes mobilizadas pelo sujeito ao tomar a palavra. Assim, em nosso corpus, buscamos delinear as diferentes vozes que emergem nos depoimentos, a fim de compreender as representações acerca dos Direitos Humanos. Não se trata de averiguar a veracidade ou não das respostas obtidas, mas os sentidos que são produzidos ao enunciar sobre o tema em questão.

Tomar a palavra é, inevitavelmente, engajar-se em relações de alteridade (eu e o(s) outro(s)), balizadas por formações imaginárias, isto é, por um jogo de representações "que designam o lugar que A e B se atribuem cada um a si e ao outro, a imagem que eles se fazem de seu próprio lugar e do lugar do outro" (PECHEUX, 1969/1997, p. 82). Novamente, considerando os depoimentos dados pelos sujeitos dessa investigação, questionamo-nos quais são as representações por eles construídas acerca do tema Direitos Humanos, tendo em vista a formação discursiva ${ }^{4}$ da qual enunciam.

Partimos da hipótese de que existe uma tensão nos dizeres dos PMs, isto é, um conflito de vozes entre o discurso institucional e o discurso não legitimado institucionalmente, independentemente da formação dos pesquisados, o que aponta para a existência de uma memória discursiva que é ora negada, ora relativizada, mas que não pode ser simplesmente apagada pelo fato de se ocupar um lugar profissional determinado. E, nesse sentido, nosso intuito aqui é descrever e interpretar como essa memória é ressignificada por tais sujeitos.

Tendo em vista essas considerações, elaborou-se um questionário de forma a permitir que os sujeitos tomassem uma posição acerca do tema Direitos Humanos $^{5}$. Foram entrevistados nove militares de um Batalhão de Polícia Militar no interior de Minas Gerais, conforme seu período de formação na instituição ${ }^{6}$. As entrevistas foram gravadas e posteriormente transcritas. A partir da leitura dos depoimentos foram, então, delineadas as representações discursivas construídas pelos policiais.

A divisão dos participantes em três grupos, conforme o tempo de atuação na Polícia Militar, permitiu-nos investigar a hipótese de que existe uma tensão em seus dizeres (conflito entre as vozes do discurso institucional e o discurso não legitimado institucionalmente), independentemente da formação dos pesquisados. Os grupos foram assim organizados:

\footnotetext{
3 Tal pressuposto refere-se ao esquecimento n. 1, elaborado por Pêcheux (1975/1997). O esquecimento n. 2 se encontra no plano da enunciação e se refere ao fato de que, ao falarmos, utilizamos certas expressões em detrimento de outras (esquecemo-nos destas), produzindo a ilusão da naturalidade entre palavra e coisa.

4 A formação discursiva se refere ao que "numa formação ideológica dada, isto é, a partir de uma posição dada numa conjuntura dada, determinada pelo estado de luta de classes, determina o que pode e deve ser dito (articulado sob a forma de uma arenga, de um sermão, de um panfleto, de uma exposição, de um programa etc.)" (PÊCHEUX, 1975/1997, p. 160).

5 Quando necessárias, foram feitas intervenções durante a entrevista com os participantes, de forma a elucidar as respostas.

6 As entrevistas foram feitas no ano de 2013.
} 
$\checkmark$ Grupo 1: policiais militares com até 5 anos de atuação profissional - entrevistados 1 a 3

$\checkmark$ Grupo 2: policiais militares entre 6 a 20 anos de atuação profissional entrevistados 4 a 6

$\checkmark$ Grupo 3: policiais militares entre 21 a 30 anos de atuação profissional entrevistados 7 a 9

O perfil dos policiais entrevistados pode ser visualizado na Quadro 1:

\begin{tabular}{|l|l|l|l|l|l|}
\hline Policial & Sexo & Idade & $\begin{array}{l}\text { Tempo de } \\
\text { profissão }\end{array}$ & $\begin{array}{l}\text { Possui curso } \\
\text { específico de } \\
\text { Direitos Humanos }\end{array}$ & Escolaridade \\
\hline Entrevistado 1 & Masculino & 26 & 3 anos & Sim & $\begin{array}{l}\text { Superior } \\
\text { incompleto }\end{array}$ \\
\hline Entrevistado 2 & Feminino & 30 & 4 anos & Sim & $\begin{array}{l}\text { Superior } \\
\text { incompleto }\end{array}$ \\
\hline Entrevistado 3 & Masculino & 27 & 5 anos & Sim & $\begin{array}{l}\text { Superior } \\
\text { incompleto }\end{array}$ \\
\hline Entrevistado 4 & Masculino & 27 & 7 anos & Sim & $\begin{array}{l}\text { Superior } \\
\text { completo }\end{array}$ \\
\hline Entrevistado 5 & Masculino & 38 & 18 anos & Sim & Ensino médio \\
\hline Entrevistado 6 & Masculino & 44 & 19 anos & Sim & Ensino médio \\
\hline Entrevistado 7 & Masculino & 42 & 21 anos & Sim & Ensino médio \\
\hline Entrevistado 8 & Masculino & 46 & 24 anos & Não & Ensino médio \\
\hline Entrevistado 9 & Masculino & 45 & 25 anos & Não & Ensino médio \\
\hline
\end{tabular}

\section{Quadro 1}

As representações acerca do tema Direitos Humanos foram expressas por meio de enunciados que sintetizam regularidades de sentidos e que são visualizados por sequências discursivas enumeradas em que se podem entrever as análises empreendidas ${ }^{7}$. A partir dos enunciados por nós depreendidos, buscamos investigar como, no fio horizontal do dizer (intradiscurso), irrompem-se as vozes e já ditos historicamente construídos e consolidados (interdiscurso), apontando para a existência de uma memória discursiva que constitui as falas sem que se tenha controle disso. 


\section{REPRESENTAÇÕES E EMBATE DE VOZES NO DISCURSO SOBRE OS DIREITOS HUMANOS}

A partir da leitura dos depoimentos, delineamos quatro representações acerca dos Direitos Humanos. Aqui as separamos por razões didáticas, mas salientamos que elas se interligam e se sobrepõem em um contínuo jogo de unidade e dispersão dos sentidos. Passemos à análise da primeira representação.

A primeira representação que elencamos diz respeito à importância dos Direitos Humanos ${ }^{8}$ para o policial e pode ser expressa pelo enunciado: Os Direitos Humanos são importantes porque asseguram o bom trabalho da Polícia Militar. Esse enunciado pode ser observado nas seguintes sequências discursivas:

(SD1) “/.../ contribuindo aí de forma positiva no aperfeiçoamento e na qualidade do desenvolvimento profissional." (Ent. 1)

(SD2) “/.../ primeiro pro policial ter outra visão da polícia, pra ele ser mais qualificado pra sociedade ver que o policial tem qualificação pra ele respeitar mais os direitos fundamentais do cidadão /.../ depois da ditadura militar. Isso aí é requisito essencial /.../" (Ent. 2)

(SD3) “/../desperta um olhar diferente sobre aquela visão pelo menos que eu tinha antes de polícia sociedade /.. / um conceito diferente /.../ um tá ligado ao outro e um serve para proteger é a polícia /.../" (Ent. 3)

(SD4) " /.../ Porque nós somos responsáveis direto por fazer o Direitos Humanos acontecer /.../ Nós somos o principal representante do estado e nós temos que fazer o que garantir o direito à vida, direito à saúde, isto é tudo responsabilidade do policial como policial militar eu tenho que ter esta responsabilidade como princípio. Direito da dignidade da pessoa humana tá na nossa missão visão isso é crucial pro policial militar.” (Ent. 6)

(SD5) "Porque é fundamental /.../ hoje aplicar os Direitos Humanos" (Ent. 5) (SD6) “/.../ na atualidade hoje é a sociedade exige né /.../” (Ent. 7)

(SD7) “/.../ hoje nós vivemos num país democracia né e hoje é na polícia nós trabalhamos na mais transparência possivel então eu acho que todo militar tem que é tem que saber os direitos os direitos e os deveres que o cidadão tem /.../ "(Ent. 8)

(SD8) "Se você tem conhecimento da matéria de Direitos Humanos a gente já vai agir com certeza a com mais cautela com mais sabedoria né porque querendo ou não ela é tipo assim uma lei ou um documento que a pessoa pode cobrar da gente /.../" (Ent. 9)

A justificativa para a importância do conhecimento dos Direitos Humanos parece sustentar-se, nas respostas dos policiais, pela voz do discurso democrático. Contudo, a forma como essa voz emerge no fio do dizer (des)vela o trabalho dos sentidos na história e produz significações distintas. Para os policiais de formação mais antiga, o discurso democrático adquire quase o status de uma atual exigência institucional, fortemente marcada no uso do advérbio de tempo 'hoje'. O que parece vir à tona, aqui, são representações acerca da Instituição

8 Representação construída a partir das respostas à pergunta 2: Você concorda com a existência e importância do curso ou disciplina de Direitos Humanos na formação e qualificação profissional? Por quê? 
Polícia Militar que retomam um período histórico, na nação brasileira, em que tais direitos não eram considerados. Trata-se, pois, de um movimento dialógico que delineia uma visão de Polícia situada ora numa sociedade moderna, ora numa sociedade regida pela ditadura, e que pode ser marcado pelas expressões 'a Polícia Militar de hoje' x 'a Polícia Militar de antigamente'. Dessa forma, enunciar sobre Direitos Humanos é estar nesse espaço de tensão e conflito que advém não da mera vivência do policial na instituição, mas de uma memória discursiva, cujos efeitos de sentido estão cristalizados na história.

Por outro lado, apesar dessa memória também aparecer nas respostas dos policiais de formação mais recente (pois se trata de uma tensão constitutiva), parece-nos que a ênfase recai nos ideias democráticos (e não na oposição com os pressupostos ditatoriais), pautados na liberdade, no respeito, na cidadania, obtidos, nas instituições, sobretudo por uma gestão de qualidade. Ou seja, os Direitos Humanos são importantes não simplesmente porque hoje a sociedade exige (SD6) ou pelo fato de que se você tem conhecimento da matéria de direitos humanos a gente já vai agir com certeza com mais cautela (SD8), mas porque o direito da dignidade da pessoa humana tá na nossa missão visão isso é crucial pro policial militar (SD4), pra sociedade ver que o policial tem qualificação (SD2).

Uma outra voz que é recorrente nas discussões sobre Direitos Humanos e que é frequentemente evocada pela mídia é a expressa pela sequência abaixo:

(SD9) “/.../ concordar concordar não concordo não. Direito dos Manos. Não é pela forma com que é redigida sim mas pela forma como ele é executado não. Porque ele não atende à população nem a população assim eu falo quando o é o policial é acusado injustamente de alguma coisa mesmo o quando o filho de algum cidadão é morto o Direitos Humanos não vai lá por causa de pra ver o que a família tá precisando só quer olhar parece que em relação ao cidadão infrator." (Ent. 4)

Ao ser questionado sobre a presença e importância do curso de Direitos Humanos na formação do policial, o participante inscreve-se em um discurso de resistência contra a voz institucional (concordar concordar não concordo não) e traz à tona a voz do senso comum. Apesar de não ter sido um dizer recorrente nos depoimentos (pelo menos não no nível intradiscursivo), problematizamos seus efeitos aqui, uma vez que assumimos que os sentidos são sócio-historicamente construídos e não se originam, portanto, no indivíduo. Em outras palavras, trata-se de uma voz que circula socialmente e que pode estar presente nos outros dizeres, ainda que silenciada.

A expressão Direito dos Manos funciona como forma de oposição à própria filosofia dos Direitos Humanos, atribuindo a esta a falsa ideia de que apenas os infratores da lei são beneficiados com direitos, isto é, de que não atende à população, só quer olhar parece que em relação ao cidadão infrator. Ideia essa que, arriscamo-nos a dizer, é reforçada pela percepção de impunidade que marca a sociedade brasileira. Assim, a expressão Direito dos Manos aponta não apenas para a falta de reflexão do policial em relação à complexidade e profundidade do tema, mas faz resvalar, pela linguagem, os conflitos inerentes à profissão, como quando o policial é acusado injustamente de alguma coisa. 
A segunda representação refere-se ao conceito, propriamente dito, de Direitos Humanos e pode ser expressa pelo enunciado 9 : Os Direitos Humanos são um conjunto de leis que protegem os cidadãos em várias esferas de sua vida.

Vejamos as sequências discursivas:

(SD10) “É a proteção dos direitos fundamentais que a pessoa tem que ter para melhor qualidade de vida /.../ mas tem que tá presente na mente das pessoas. Não adianta ta ali só na carta dos Direitos Humanos, tal, mas tem que tá incutido na sociedade. O jurídico mesmo é complicado a gente falar certinho as palauras e tal. Mas a essência é esta." (Ent. 2)

(SD 11) "É um direito voltado para a humanidade né assim. O o lado humano das pessoas que garante a humanidade os direitos fundamentais do cidadão." (Ent. 4)

(SD12) “/.../ definição eu não tenho uma definição mental pra falar aqui agora mas tenho uma visão bem ampla sobre minoria, sobre grupo vulnerável direito daqueles diferentes que fala criança, adolescente, idoso /.../ acho que Direitos Humanos pra proteger o direito de todos e de alguns grupos especiais que precisam dessa proteção.” (Ent. 6)

(SD13) "Eu eu vejo Direitos Humanos é nada mais do que a gente fazer cumprir o que ta lá na Constituição Federal garantir aqueles direitos básicos e mais uns outros agregados.

Intervenção: quais são esses direitos? Cite alguns aí.

Olha é é ai vem um conjunto né transporte, moradia, médico é escola e vários outros." (Ent. 7)

(SD14) "Direitos Humanos /.../ sem olhar sem olhar no livro lá é direito é direito da vida direito da pessoa direito assim Direitos Humanos porque é direito da pessoa Direitos Humanos bom eu entendo isso. Direitos Humanos direito do cidadão ali.” (Ent. 9)

Apesar de as respostas apresentarem diferenças em termos de formulação, o que inclusive diz respeito à familiaridade com práticas de letramento e escolarização, em geral, exploram os efeitos de sentido da palavra 'humanos', como se tais direitos fossem naturais, óbvios, afinal, nada mais do que a gente fazer cumprir o que ta lá na Constituição Federal garantir aqueles direitos básicos (SD13), um direito voltado para a humanidade (SD11), direito da vida (SD14). Contudo, chama-nos a atenção a tentativa de 'estancar' o conflito que a aplicação dos direitos humanos (ou de qualquer outro!) faz vir à baila, caso contrário, não haveria necessidade de se afirmar que ele tem que tá presente na mente das pessoas, não adianta ta ali só na carta dos direitos humanos, tal, mas tem que tá incutido na sociedade (SD10).

Conflito esse que aparece no depoimento do entrevistado 5:

(SD15) “/.../ eu defino como um conceito bom só que às vezes eu discordo de algumas doutrinas de Direitos Humanos apesar que o Direitos Humanos ele não é voltado contra a pessoa e sim contra o estado. Um exemplo uma vítima de roubo ou uma vítima de homicídio né às vezes naquela situação que a polícia

9 Representação construída a partir das respostas à pergunta 4: Como você define o conceito jurídico de Direitos Humanos? 
faz a prisão ou a apreensão do cidadão infrator é ele age as vezes pela emoção e acaba excedendo ali na sua atividade a os Direitos Humanos ele acaba que entrando com a ação né muitas vezes contra o estado. Não contra o policial mas contra o estado.

Intervenção: certo. Mas o que é Direitos Humanos?

A Direitos Humanos é respeitar né a dignidade humana respeitar o cidadão entendeu é isso." (Ent. 5)

Ao ser questionado sobre a definição jurídica do conceito de Direitos Humanos, irrompem, no fio do dizer, sentidos semelhantes aos que discutimos na SD9, que funcionam, discursivamente, como mecanismo de resistência aos saberes institucionalmente legitimados. O sujeito encontra-se no espaço de tensão, em que a voz institucional (conceito bom, respeitar o cidadão) encontra/ confronta a voz do senso comum e da própria prática profissional. Ressoam aqui os sentidos da expressão Direito dos Manos, ainda que se afirme que os direitos humanos ele não é voltado contra a pessoa e sim contra o estado, mostra-se que há uma memória que fala antes do sujeito (observe-se o advérbio 'não', que funciona polifonicamente, dialogando com a voz que afirma que 'sim', que os direitos são contra a pessoa e, no caso, contra um policial questionado em sua ação).

Vale salientar que, apesar dos infratores não respeitarem os Direitos Humanos, não significa que eles não mereçam tê-los. Para ficar clara a situação, é preciso entender a diferença de abordagem para com o infrator humano e para os comportamentos irregulares e inaceitáveis do infrator. Esse é um conflito que o policial sofre diariamente e precisa compreender para experienciar a filosofia dos Direitos Humanos em sua prática. Como afirma a DPSSP n 3.01.05/2010, os Direitos Humanos "são todos os direitos que possuímos, pelo simples fato de sermos seres humanos, que nos permitem viver com dignidade" (MINAS GERAIS, 2010, p. 14).

Quanto à terceira representação, observa-se que, ao serem indagados sobre as possiveis dificuldades que encontram para aplicar os Direitos Humanos na atividade policial, bem como sobre os direitos mais respeitados, os policiais enunciam dizeres que podem ser expressos no seguinte enunciado ${ }^{10}$ : $O$ policial (des)respeita, em suas ações, os Direitos Humanos ao ter que fazer uso da força fisica ou cercear o direito de ir e vir.

(SD16) "Sim. Porque em algumas ações é necessário a gente utilizar de força física. Em algumas intervenções policiais /.../ ele estando agressivo torna-se necessário aí o policial agir de forma mais enérgica pra conter a ação de certa forma agressiva dele com o policial militar." (Ent. 1)

(SD17) “/.../ a gente tá diuturnamente aí né fazendo abordagem ali em tese ceifando o direito de ir vir do cidadão para garantir a tranquilidade até mesmo dele próprio." (Ent. 1)

(SD18) “/.../ Primeiro, a própria população já tem uma resistência a polícia /... chega lá pra orientar e pessoa já acha que você tá lá pra invadir o espaço

10 Enunciado depreendido da análise às repostas 5 (Você encontra dificuldades para aplicar os Direitos Humanos na atividade policial? Quais?), 7 (Em sua opinião, quais são os Direitos Humanos mais respeitados nas ações policiais?), 8 (A seu ver, quais são os Direitos Humanos mais difíceis de serem respeitados nas ações policiais?) e 10 (O que pode dificultar a aplicação dos Direitos Humanos na atuação policial militar?). 
dela /.../ Formação também /.../ você ainda ouve discurso assim muito é ditadores_né, ah tem que fazer é isso mesmo e tal, você ainda ouve algumas coisas meio absurdas assim então acho que tinha que ser dada uma carga horária de Direitos Humanos mais assim incisiva na polícia, pra tentar mudar a mente das pessoas /.../" (Ent. 2)

(SD19) “/.../ o que a gente pelo menos no meu caso é o que a gente fica tentando se controlar se controlar é a questão de integridade física.” (Ent. 3)

(SD20) “/.../ mesmo que eu vou parcialmente obter do direito de ir e vir temporariamente tirar esse direito dele /.../ o que dificulta é o questionamento dele é indignação de estar sendo abordado porque geralmente eles falam assim eu não sou ladrão sou trabalhador /.../" (Ent. 4)

(SD21) “/.../ É a questão de manter o autor ileso porque toda ação tem uma reação /.../ acho que é de manter ele ileso a partir do momento que ele reage". (Ent. 5)

(SD22) "Não eu não vejo. A dificuldade que eu vejo é de algumas pessoas não conhecer eu falo isso os próprios policiais não lê sobre o assunto achar que os Direitos Humanos é pra proteger bandido a dificuldade é essa mas questão de conhecimento eu acho que não tem não." (Ent. 6)

(SD23) “/.../ às vezes a gente tem que usar aí da força física pra dominar uma situação e ter que ali até é lesionar o cidadão com uso de bastão /.../ ou a gente acerta na perna pra evitar um mal maior eu vejo ali que é respeitada a dignidade do cidadão ali também.” (Ent. 7)

(SD24) "A hoje encontra. Hoje na atual circunstância. Devido é devido à falta de de de respeito que o cidadão tem com o policial militar às vezes o policial militar vai dialogar com o cidadão respeitando os limites dos direitos do cidadão." (Ent. 8)

(SD25) "A o direito de ir e vir do cidadão né é um direito que a gente respeita muito $a$ integridade física do cidadão que hoje a gente usa de meios moderados não de violência.” (Ent. 8)

Independentemente do tempo de atuação na instituição, pode-se notar, pelas sequências, que o uso da força policial, bem como o impedimento do direito de ir e vir do cidadão, nas diversas abordagens, causa desconforto, apresentando-se, pois, como ponto de tensão na relação dos policiais com os Direitos Humanos. A voz da prática, constituída das percepções dos sujeitos em relação às especificidades e contingências de sua atuação profissional, vem à tona de forma a questionar o imaginário acerca desses Direitos.

Falar de força física é rememorar um passado em que não havia regras ou limites para seu uso. Diferente de hoje na atual circunstância (SD24), hoje a gente usa de meios moderados não de violência (SD25). Assim, diriamos que o exercício da profissão coloca o policial em uma zona fronteiriça, em que se tem que lidar com o fato de que se está em tese ceifando o direito de ir vir do cidadão para garantir a tranquilidade até mesmo dele próprio (SD17) ou decidir acerca de como manter ele [infrator] ileso a partir do momento que ele reage (SD21). Dito de outro modo, exercer a profissão de PM envolve, até pra evitar um mal maior (SD23), escolhas que não dependem apenas de treinamento, por exemplo, ou de se memorizar um conjunto de leis, mas de um contínuo ressignificar, pautado na reflexão da própria prática. 
Emerge, no fio horizontal do dizer, a contradição ${ }^{11}$ que constitui os sujeitos e que é marcada na tentativa de camuflar os conflitos, a ponto, inclusive de se dizer que não se encontram dificuldades para aplicar os Direitos Humanos e logo em seguida enunciá-las (SD22). Tal tentativa aparece, por exemplo, na ilusão da pacificidade total', em que se atribui ao cidadão civil a culpa da abordagem excedente do policial (pois ele estando agressivo torna-se necessário aí o policial agir de forma mais enérgica (SD16)) ou na crença de que mais cursos resolveriam os problemas (SDs 18 e 22).

O uso da força aponta para a delicada questão da violência policial e para seus modos de ocorrência em uma sociedade tida como democrática (GUIMARÃES; TORRES \& FARIA, 2005). Lidando em seu cotidiano com situações que tocam diretamente pontos de tensão social, percebe-se que o PM vivencia o conflito de entender que é protetor tanto quanto é merecedor dos Direitos Humanos e que a dicotomia 'polícia' x 'sociedade', "a descaracterização do policial como um integrante da sociedade civil, com os mesmos direitos e deveres e, em muitos casos, tendo esses direitos feridos, promove barreiras ao seu diálogo com a população" (NOBRE \& PINHEIRO, p. 191).

Finalmente, ao serem questionados se sentem-se um protetor de todos os Direitos Humanos ${ }^{12}$, pode-se entrever a quarta representação, expressa pelo enunciado: O policial é, pela função que exerce, protetor dos Direitos Humanos.

(SD26) "Sim. Pois como promotor de segurança pública é meu dever proteger incentivar a propagação dos Direitos Humanos.” (Ent. 1)

(SD27) "Claro como policial e como cidadão também nos pequenos gestos você tá protegendo os direitos das pessoas /.../ Claro que a gente tem falhas né eu sou ser humano lógico, mas eu tento fazer as coisas certo.” (Ent. 2)

(SD28) “/.../ se sou um profissional que tem que cumprir e fazer cumprir a leis então de certo forma eu também to garantindo os direitos do cidadão.” (Ent. 4) (SD29) "Sempre uai. Sempre. No dia a dia quando eu ponho a minha farda né eu já to ali fazendo cumprir os Direitos Humanos_/.../" (Ent. 7)

(SD30) "Olha a gente tenta ser usar todos os meios e direitos de ir vir do cidadão né eu acho que nós fomos preparados pra isso. Talvez possa acontecer de que numa intervenção entre uma e outra pode acontecer um excesso /.../" (Ent. 8)

O lugar social ocupado pelos policiais aparece como argumento suficiente, em seus dizeres, para legitimar o seu papel como protetor dos direitos humanos. Nesse sentido, apropriam-se da voz institucional para projetar a imagem de si mesmos como profissionais que são promotores da segurança pública (SD26) e que, ao colocarem a farda, já to ali fazendo cumprir os direitos humanos (SD29). Nota-se a apropriação do discurso institucional no uso de verbos e expressões que denotam obrigatoriedade (tem que cumprir (SD28) e é meu dever proteger (SD26)).

Aliás, cumpre mencionar que o Ent. 4, mesmo tendo afirmado na resposta à questão 2 que não concorda com os direitos humanos (SD9), responde positivamente à questão 12 (SD28). Não se trata aqui de averiguar a veracidade ou fazer conjecturas sobre sua atuação como policial. Antes, trata-se de compreender co-

\footnotetext{
11 Contradição que aqui assumimos como constitutiva, fruto da natureza heterogênea e polifônica da própria linguagem, e não como "problema" a ser resolvido.

12 Pergunta 12 do questionário (Você se sente um protetor de todos os Direitos Humanos? Comente).
} 
mo os sentidos se movimentam em um jogo de unidade e dispersão, do mesmo e do diferente. Em outras palavras, como o sujeito ressignifica os discursos que o circundam e o constituem, sem que, muitas vezes, se dê conta disso. A ilusão de completude (o desejo de construir perante o outro uma imagem una e completa) esbarra na percepção da falta, na constatação de que a gente tem falhas (SD27).

Cumpre dizer que a justificativa dos policiais para a defesa de que são protetores dos Direitos Humanos pela função que exercem é pouco significativa em vista da profundidade e complexidade dos conceitos verificados, pois, como afirma Balestreri:

Em nível pessoal, é fundamental que o cidadão policial sinta-se motivado e orgulhoso de sua profissão. Isso só é alcançável à partir de um patamar de "sentido existencial”. Se a função policial for esvaziada desse sentido, transformando o homem e a mulher que a exercem em meros cumpridores de ordens sem um significado pessoalmente assumido como ideário, o resultado será uma autoimagem denegrida e uma baixa autoestima. Resgatar, pois, o pedagogo que há em cada policial, é permitir a ressignificação da importância social da polícia, com a consequente consciência da nobreza e da dignidade dessa missão. A elevação dos padrões de autoestima pode ser o caminho mais seguro para uma boa prestação de serviços. (BALESTRERI, 2003, p. 25).

\section{CONSIDERAÇÕES FINAIS}

As transformações sócio-históricas e políticas incidem no desenvolvimento de conceitos cada vez mais amplos e abrangentes sobre os Direitos Humanos, o que reforça a necessidade de problematizá-los na formação de policiais militares, buscando sua maior compreensão e proteção. Nos dizeres analisados, nota-se o embate de vozes advindos tanto do entendimento da importância dos Direitos Humanos quanto de dificuldades para aceitar a extensão e aplicação desses direitos para todos os seres humanos, apesar da Instituição promover e divulgar a construção de diretrizes e normas sobre a temática na formação e qualificação profissional.

Observa-se que há uma memória discursiva acerca da própria instituição Polícia Militar que constitui os sujeitos e que molda sua percepção acerca dos Direitos Humanos. Tal memória é sustentada por sentidos que se inscrevem na historicidade brasileira enquanto nação que passou de um regime ditatorial para uma república democrática. Independentemente do tempo de atuação do policial na Instituição, os dizeres dos participantes da pesquisa são marcados pelo confronto de vozes oriundas do discurso Institucional e do discurso não legitimado institucionalmente (tais como a voz do senso comum, reforçada sobretudo pelas instituições midiáticas), o que comprova a hipótese formulada.

A análise aqui empreendida aponta, a nosso ver, para a necessidade de se trabalhar, nos cursos de formação e treinamentos, com os conflitos e as tensões inerentes à profissão, não no sentido de 'resolvê-los', mas de promover olhares outros que venham incidir sobre a atuação policial. Entendemos que a discussão sobre os Direitos Humanos, pelos policiais, não pode se restringir à exposição de um conjunto de princípios teóricos, sistematicamente formalizados. An- 
tes, a fim de que se possam contemplar deslocamentos nas representações e, consequentemente, no exercício desses direitos, é necessário que sejam dadas, aos policiais, oportunidades de ressignificarem sua prática, a partir das memórias que os constituem e das condições que experienciam em seu cotidiano profissional (como os desafios frente à crescente criminalidade e impunidade e às condições, por vezes precárias, de trabalho).

A problematização dos Direitos Humanos na formação policial se justifica no intuito de provocar a desconstrução de conceitos naturalizados, pautados em visões simplistas (como, por exemplo, a de que os direitos humanos se restringem à defesa dos direitos de infratores) e homogeneizantes de sujeitos, cultura e sociedade.

\title{
HUMAN RIGHTS: DISCURSIVE REPRESENTATIONS IN THE VOICES OF POLICE OFFICERS
}

\begin{abstract}
This article aims at investigating discursive representations concerning the Human Rights built by police officers with the purpose of problematizing the incidence of such discursivity in the courses and training of these professionals. We assume that there is tension between the institutional and the non-institutional discourse, regardless the year the police officers took their training courses.
\end{abstract}

Keywords: Human Rights. Discourse Analysis. Police Training Course.

\section{REFERÊNCIAS}

BAKHTIN, M. (Volochinov). (1929). Marxismo e Filosofia da Linguagem: problemas fundamentais do Método Sociológico na Ciência da Linguagem. Tradução Michel Lahud e Yara Frateschi Vieira. 9. ed. São Paulo: Hucitec, 2002.

BAKHTIN, M. (1929). Problemas da poética de Dostoiévski. Tradução Paulo Bezerra. 3 ed. Rio de Janeiro: Forense Universitária. 2008.BAKHTIN, M. (1953). Estética da Criação Verbal. Tradução Paulo Bezerra. São Paulo: Martins Fontes, 2003. BALESTRERI, R. B. Direitos Humanos: coisa de polícia. Passo Fundo: Edições Capec: Gráfica Editora Berthier, 2003.

BENEVIDES, M. V. Educação em direitos humanos: de que se trata? Palestra de abertura do Seminário de Educação em Direitos Humanos, São Paulo, 18 fev. 2000. Disponivel em: <http://www.dhnet.org.br/dados/boletins/edh/br/boletim1.html\#Dequesetrata>. Acesso em: 7 jan. 2015.

BRASIL. Constituição (1988). Constituição da República Federativa do Brasil: promulgada em 5 de outubro de 1988. 40. ed. São Paulo: Saraiva, 2007.

BRASIL SEDH/PR. Programa Nacional de Direitos Humanos. Brasília, 2010.

FERREIRA FILHO, M. G. Direitos Humanos Fundamentais. São Paulo: Saraiva, 2007. 
GUIMARÃES, J. G.; TORRES, A. R. R. \& FARIA, M. R. G. V. Democracia e violência policial: o caso da policia militar. Psicologia em Estudo, v. 10, n. 2, 2005. p. 263-271.

HERKENHOF, J. B. Direitos Humanos - A construção de uma utopia. Aparecida: Santuário, 1997.

MENDONÇA FILHO, M. C. et al. Polícia, direitos humanos e educação para a cidadania. In: NEVES, P. S.; RIQUE, C. D. G. \& FREITAS, F. F. B. (Orgs.). Polícia e democracia: desafios à educação em direitos humanos. Recife: Gajop; Bagaço, 2002. p. 85-110.

MINAS GERAIS. Polícia Militar. Comando-Geral. Diretriz para Produção de Serviços de Segurança Pública $n^{\circ}$ 3.01.05/2010-CG: Regula a Atuação da Polícia Militar de Minas Gerais segundo a filosofia dos Direitos Humanos. Belo Horizonte: PMMG, 2010.

NOBRE, M. T. \& PINHEIRO, F. L. Superando a dicotomia sociedade $\mathrm{x}$ policial militar: relato de uma experiência. In: NEVES, P. S.; RIQUE, C. D. G. \& FREITAS, F. F. B. (Orgs.). Policia e democracia: desafios à educação em direitos humanos. Recife: Gajop; Bagaço, 2002. p. 171-193.

ORLANDI, E. P. Análise do Discurso: princípios e procedimentos. 6. ed. Campinas: Pontes, 2005.

PÊCHEUX, M. (1969). Análise Automática do Discurso (AAD-69). In: GADET, F.; HAK, T. (Org.). Por uma Análise Automática do Discurso: uma introdução à obra de Michel Pêcheux. Tradução Eni Orlandi. Campinas: Unicamp, 1997. p 61-151. PÊCHEUX, M. (1975). Semântica e Discurso: uma crítica à afirmação do óbvio. Tradução Eni Puccinelli Orlandi et al. Campinas: Unicamp, 1997.

Recebido em 07-06-2016.

Aprovado em 04-07-2016. 